\section{Weekly exercise programme with foot exercises to improve physical function in community-dwelling pre- frail older adults}

Takahiro Nishida ${ }^{1,2}$; Rieko Nakao ${ }^{2}, \mathrm{PhD}$; Mika Nishihara ${ }^{2}, \mathrm{PhD}$; Ryoko Kawasaki ${ }^{2}$, PhD; Sumihisa Honda ${ }^{2}$, PhD

\begin{abstract}
Background. To investigate the effect of an exercise programme incorporating foot exercises on improving physical function among community-dwelling pre-frail older adults.
\end{abstract}

Method. 13 men and 59 women (mean age, 78.5 years) with pre-frail status joined the exercise programme (a 90-minute session once a week for 3 months). The main exercises comprise strengthening of the muscles in the arms, trunk, hips, and knees, as well as 10 minutes of foot exercises that comprise toe grasp training or ankle joint stretches/ strengthening. Subjective physical function was measured using the motor ability domain of the frailty checklist. Objective physical function was assessed by a single nurse using the toe grip strength (TGS), fiverepetition sit-to-stand test (5STS), one-leg standing duration with eyes open (OLS), 5-m walk test (5WT), and timed up-and-go test (TUGT).

Results. In terms of subjective physical function, there was a significant improvement in leg muscle strength, walking endurance, and fear of falling. In terms of objective physical function, the mean TGS increased from $2.6 \mathrm{~kg}$ to $2.9 \mathrm{~kg}$ for the left side $(\mathrm{p}=0.005)$ and from $2.7 \mathrm{~kg}$ to $3.0 \mathrm{~kg}$ for the right side $(\mathrm{p}=0.004)$. Time taken for 5STS decreased from $9.7 \mathrm{~s}$ to $9.1 \mathrm{~s}(\mathrm{p}=0.037)$, and time taken for $5 \mathrm{WT}$ decreased from $4.5 \mathrm{~s}$ to $4.2 \mathrm{~s}(\mathrm{p}=0.003)$. However, time taken for OLS and TUGT (balance ability) did not improve significantly.

Conclusion. Exercise programme incorporating foot exercises can improve walking ability and leg muscle strength in community-dwelling pre-frail older adults. Nonetheless, the fall risk remains if balance ability is not improved.

Key words: Accidental falls; Frail elderly; Muscle strength; Toes

\section{ORIGINAL ARTICLE}

\footnotetext{
Sasebo-Yoshii Community

Comprehensive Support Center, Japan

2 Department of Public Health Nursing, Nagasaki University Graduate School of

Biomedical Sciences, Japan
}

Correspondence to: Sumihisa Honda, Department of Public Health Nursing, Nagasaki University Graduate School of Biomedical Sciences, 1-7-1 Sakamoto, Nagasaki 852-8520, Japan. Email: honda@nagasaki-u.ac.jp

\section{INTRODUCTION}

According to a 2013 report from the Japanese Ministry of Health, Labor, and Welfare, 'falls and fractures' and 'joint disease' combined were the leading cause of long-term care among older adults in Japan, accounting for $22.7 \%$ of all causes. ${ }^{1}$ Falls, fractures, and joint disease can cause locomotive syndrome, ${ }^{2}$ and prevention is a priority for older adults. ${ }^{3-6}$ Frail older adults are at high risk of falls and joint disease owing to muscle weakness and poor balance. ${ }^{7,8}$ Frailty can be categorised as nonfrailty, pre-frailty, and frailty. ${ }^{7,9}$ Pre-frailty is defined as the presence of at least one of the following five indicators: unintentional weight loss, weakness, exhaustion, slowness, and low physical activity; ${ }^{9}$ 
early intervention is important at this stage. ${ }^{7,9}$ In 2006, the Japanese Ministry of Health, Labor, and Welfare launched a 3-month exercise programme for community-dwelling pre-frail older adults to prevent falls by improving physical function. ${ }^{10}$ The programme was found to save long-term care costs but was not effective in improving self-reported physical function (measured by the frailty checklist). However, physical measurements were not assessed, and the frailty checklist alone may not accurately reflect the physical ability. ${ }^{11}$

Foot and ankle functions, particularly toe grip strength (TGS), are considered the most important physical function associated with the risk of falls among older adults. ${ }^{12,13}$ TGS and plantar tactile sensation are closely associated with balance ability among older adults. ${ }^{14}$ Cutaneous mechanoreceptors are located in the plantar fascia and the muscular, articular, and periarticular structures of the feet. ${ }^{15,16}$ Cutaneous afferent inputs from the sole of the foot provide information to control posture and locomotion. ${ }^{17}$ Toe elevation angle is an index of dynamic balance ability for pre-frail older adults. ${ }^{18}$ However, these findings are derived from crosssectional studies, and the effect of improving TGS remains unknown. Characteristics of older adults are heterogeneous. ${ }^{19}$ Thus, this study aimed to investigate the effect of an exercise programme incorporating foot exercises on improving physical function among community-dwelling pre-frail older adults.

\section{METHODS}

This pre- and post-intervention study was conducted between May 2013 and January 2016 and was approved by the Ethics Committee of Nagasaki University Graduate School of Biomedical Sciences (reference: 17081085). Written informed consent was obtained from each participant before the intervention.

The frailty checklist was mailed to all 1346 community-living older adults aged $\geq 65$ years in the area. Of these, $958(71.2 \%)$ returned the completed frailty checklist and 144 (15.0\%) of them were categorised as pre-frail. The frailty checklist comprises 25 questions relating to lifestyle $(n=5)$, motor ability $(n=5)$, nutrition $(n=2)$, oral function $(n=3)$, homeboundness $(n=2)$, forgetfulness $(n=3)$, and emotions $(n=5)$. Pre-frailty is defined as having impaired motor or oral function, malnutrition, impaired lifestyle, or a total score of 10 excluding the domain for emotions. ${ }^{10}$

The 144 pre-frail older adults were invited to an interview with a public health nurse to confirm their eligibility. Their characteristics and medical history (bone and joint disease) were recorded. Of them, 72 (50.0\%) agreed to participate in a 3-month exercise programme. Of these, 13 dropped out owing to disease, declining motivation, travel, or family obligations. None was due to an adverse event (eg, a fall or experiencing pain). Finally, 59 participants (48 women and 11 men) completed the exercise programme.

The exercise programme was conducted one session per week at a daycare centre in a suburban area in southwest Japan. Each session lasts 90 minutes and comprises a medical checkup (10 minutes), warm-up (20 minutes), main exercises (40 minutes, including a 10-minute tea break), cooldown (10 minutes), and lecture (10 minutes). The warm-up and cool-down comprise mild stretching (shoulder rotation, waist rotation, stretching the arms upward, and lateral bending of the arms, hip flexors and hip extensors, and heel raises). The main exercises comprise strengthening of the muscles in the arms, trunk, hips, and knees, as well as 10 minutes of foot exercises that comprise toe grasp training or ankle joint stretches/strengthening (TABLE 1) alternately each session. The intensity of the main exercises increases progressively over 3 months. Each session was attended by a median of 10 (range, 5 to 15) participants and supervised by two nurses; the median attendance rate was 12 (range, 9 to 12) sessions.

Subjective physical function was measured using the motor ability domain of the frailty checklist. ${ }^{10}$ The domain comprises five questions, with yes scored 0 and no scored 1: (1) Do you climb stairs without holding onto a handrail or the wall? (2) Do you get up from a chair without grabbing something? (3) Can you keep walking for over 15 min? (4) Do you have a fear of falling? and (5) Have you fallen within the last year?. For (5), a fall is defined as"unintentionally coming to rest on the ground or at some other lower level, not as a result of a major intrinsic event (eg, stroke) or overwhelming hazard". ${ }^{20}$ Falls history 
TABLE 1

Description of the foot exercises

\begin{tabular}{|c|c|c|}
\hline Exercise & Instructions & Repetitions \\
\hline \multicolumn{3}{|l|}{ Toe grasp training } \\
\hline Towel gathering & $\begin{array}{l}\text { Sit in a chair and pull a towel with your toes little by little while keeping the heels } \\
\text { on the floor. }\end{array}$ & 5 \\
\hline Rolling a rubber ball & Sit in a chair and roll a rubber ball beneath your bare foot & 50 per foot \\
\hline Grasping a rubber ball & Sit in a chair and pick up a rubber ball with your toes and placing it in a box & 10 per foot \\
\hline \multicolumn{3}{|l|}{ Ankle joint stretches } \\
\hline Ankle range of motion & $\begin{array}{l}\text { Sit in a chair and place one ankle on top of the other knee and rotate the foot } \\
\text { clockwise and then counter-clockwise }\end{array}$ & $\begin{array}{l}10 \text { in each } \\
\text { direction per foot }\end{array}$ \\
\hline \multicolumn{3}{|l|}{ Ankle joint strengthening } \\
\hline Ankle plantarflexion strength & Sit in a chair and raise both legs and point both feet as much as you can for $10 \mathrm{~s}$ & 10 \\
\hline Ankle dorsiflexion strength & Sit in a chair and raise both legs and flex both feet as much as you can for $10 \mathrm{~s}$ & 10 \\
\hline
\end{tabular}

was collected at baseline and at 3 months postintervention.

Objective physical function was assessed by a single nurse using the TGS, five-repetition sit-tostand test (5STS), one-leg standing duration with eyes open (OLS), 5-m walk test (5WT), and timed up-and-go test (TUGT). ${ }^{21}$ The TGS of each side was measured using a dynamometer (Nisshin Industry, Saitama, Japan), with participants sitting and the knee bent at $90^{\circ}$. OLS of each side was measured with $60 \mathrm{~s}$ as the upper limit. All tests were conducted twice, and the better value was recorded.

Statistical analyses were performed using SPSS (Windows version 23; IBM Corp, Armonk [NY], US). Results at baseline and 3 months were compared. The McNemar test was used to compare score at baseline and post-intervention for each question of the motor ability domain. The paired t-test was performed to compare the objective measurements at baseline and post-intervention.

\section{RESULTS}

13 men and 59 women (mean age, 78.5 years) joined the exercise programme (TABLE 2). The most common joint disease occurred at the knee (54.2\%), followed by the lumbar spine (45.8\%). At baseline, $23(31.9 \%)$ participants had a history of falls in the previous 12 months. In terms of subjective physical function, there was significant improvement in leg muscle strength (questions 1 and 2) $[\mathrm{p}=0.057$ and $\mathrm{p}=0.003$, respectively], walking endurance (question
TABLE 2

Characteristics of the participants at baseline $(n=72)^{*}$

\begin{tabular}{lc}
\hline Sex & $13(18.1)$ \\
Men & $59(81.9)$ \\
Women & $78.5 \pm 5.6$ \\
Age, $y$ & $23.1 \pm 3.2$ \\
Body mass index, $\mathrm{kg} / \mathrm{m}^{2}$ & $23(31.9)$ \\
Falls in the previous 12 months & \\
Joint disease & \\
Lumbar spine & $33(45.8)$ \\
Present & $39(54.2)$ \\
Absent & \\
Hip joint & $3(4.2)$ \\
Present & $69(95.8)$ \\
Absent & \\
Knee joint & $39(54.2)$ \\
Present & $33(45.8)$ \\
Absent & \\
Ankle joint & \\
Present & \\
Absent & $64(88.9)$ \\
\hline Data are presented as mean \pm standard deviation or no. (\%) of \\
participants
\end{tabular}

3) $[p=0.031]$, and fear of falling (question 4) $[p<0.001]$ (TABle 3).

In terms of objective physical function, the mean TGS increased from $2.6 \mathrm{~kg}$ to $2.9 \mathrm{~kg}$ for the left side $(\mathrm{p}=0.005)$ and from $2.7 \mathrm{~kg}$ to $3.0 \mathrm{~kg}$ for the right side $(\mathrm{p}=0.004)$. Time taken for 5STS decreased from $9.7 \mathrm{~s}$ to $9.1 \mathrm{~s}(\mathrm{p}=0.037)$, and time taken for $5 \mathrm{WT}$ decreased 
TABLE 3

Subjective and objective physical function of participants at baseline and post-intervention $(n=59)$

\begin{tabular}{|c|c|c|c|}
\hline Physical function & Baseline $^{*}$ & Post-intervention* & $\mathrm{p}$ Value \\
\hline \multicolumn{4}{|l|}{ Motor ability domain of the frailty checklist } \\
\hline Do you climb stairs without holding onto a handrail or the wall? (No) & $51(86.4)$ & $43(72.9)$ & 0.057 \\
\hline Do you get up from a chair without grabbing something? (No) & $40(67.8)$ & $25(42.4)$ & 0.003 \\
\hline Can you keep walking for over 15 minutes? (No) & $17(28.8)$ & $7(11.9)$ & 0.031 \\
\hline Do you have a fear of falling? (Yes) & $56(94.9)$ & $43(72.9)$ & $<0.001$ \\
\hline Have you fallen within the last year? (Yes) & $19(32.2)$ & $12(20.3)$ & 0.118 \\
\hline \multicolumn{4}{|l|}{ Physical measurements } \\
\hline Right toe grip strength, $\mathrm{kg}$ & $2.7 \pm 1.1$ & $3.0 \pm 1.2$ & 0.005 \\
\hline Left toe grip strength, $\mathrm{kg}$ & $2.6 \pm 1.1$ & $2.9 \pm 1.1$ & 0.004 \\
\hline Five-repetition sit-to-stand test, sec & $9.7 \pm 3.0$ & $9.1 \pm 2.3$ & 0.037 \\
\hline One-leg standing, sec & $16.4 \pm 20.8$ & $16.7 \pm 25.2$ & 0.945 \\
\hline 5-m walk test, sec & $4.5 \pm 1.1$ & $4.2 \pm 1.1$ & 0.003 \\
\hline Timed up-and-go test, sec & $8.9 \pm 3.8$ & $8.3 \pm 1.8$ & 0.177 \\
\hline
\end{tabular}

* Data are presented as mean \pm standard or no. (\%) of participants

from $4.5 \mathrm{~s}$ to $4.2 \mathrm{~s}$ (p=0.003) [TABLE 3]. However, time taken for OLS and TUGT (balance ability) did not improve significantly.

\section{DISCUSSION}

Our findings are in agreement with those suggesting that full-range toe flexion exercises may strengthen TGS. $^{22}$ Toe-grasp training was combined with tactile stimulation through grasping a rubber ball and rolling the ball beneath the bare feet. Foot exercises that include stimulation of tactile sensation are useful for older adults to enhance physical performance. ${ }^{16,23}$ Our exercise programme with foot exercises significantly improved walking ability and leg muscle strength among pre-frail older adults. The toe flexor muscles are crucial in the propulsive force in the late stance phase of the gait cycle. ${ }^{24}$ In a crosssectional survey of 227 Japanese aged 20 to 79 years, older women aged $\geq 60$ years are predisposed to weak TGS. ${ }^{25}$ Strengthening TGS can improve walking ability, whereas muscle stretches and strengthening of the whole body including arm, trunk, hip, knee, and foot can improve muscle strength. $8,26,27$

However, static and dynamic balance ability was not significantly improved. Improved TGS was not positively correlated with improved OLS or TUGT (balance ability).TGS represents the muscle strength of the foot sole and the sural region (such as the flexor hallucis longus muscle and flexor digitorum longus muscle) but not the muscle strength of the femoral region (such as the quadriceps femoris muscle). ${ }^{24}$ Balance ability requires not only TGS but also comprehensive muscle strength of the lower limbs and hips (ie, quadriceps, iliopsoas, and gluteus medius muscles). Hence, improved TGS did not contribute to improved balance ability. Nonetheless, balance ability is associated with posture sway control, suggesting that ankle strength is important for fall prevention among older adults. ${ }^{14,28,29}$ Therefore, stretching and strengthening of the toe/ankle joint may improve balance. An exercise programme incorporating Tai Chi exercises was reported to improve balance ability but not the leg muscle strength among Japanese pre-frail older adults. ${ }^{30}$ An personalised compensation strategy for improving both balance and muscle strength is needed to prevent falls. ${ }^{19}$ Further research is needed to develop an optimal exercise programme.

Limitations of this study include the small sample size, lack of a control group, and potential selection bias. Therefore, our findings cannot be generalised to other community-dwelling pre-frail older adults and should be interpreted with caution. Moreover, confounders such as hallux valgus and joint pain might affect TGS and other physical functions.

\section{CONCLUSIONS}

Exercise programme incorporating foot exercises 
can improve walking ability and leg muscle strength in community-dwelling pre-frail older adults. Nonetheless, the fall risk remains if balance ability is not improved.

\section{ACKNOWLEDGEMENTS}

We are grateful to all participants for their valuable contributions to the study. We also thank Ms Tomoko Kawasaki from the Emukae Daycare Center for her support in data collection.

\section{DECLARATION}

The authors have no conflicts of interest to disclose.

\section{REFERENCES}

1. Ministry of Health, Labour and Welfare. http://www.mhlw. go.jp/toukei/saikin/hw/k-tyosa/k-tyosa13/dl/06.pdf. Accessed December 2016.

2. Nakamura K. The concept and treatment of locomotive syndrome: its acceptance and spread in Japan. J Orthop Sci 2011;16:489-91. Crossref

3. Muraki S, Akune T, Oka H, et al. Prevalence of falls and the association with knee osteoarthritis and lumbar spondylosis as well as knee and lower back pain in Japanese men and women. Arthritis Care Res (Hoboken) 2011;63:1425-31. Crossref

4. Suzuki T, Kim H, Yoshida H, Ishizaki T. Randomized controlled trial of exercise intervention for the prevention of falls in community-dwelling elderly Japanese women. J Bone Miner Metab 2004;22:602-11. Crossref

5. Osaki M, Tomita M, Abe Y, et al. Physical performance and knee osteoarthritis among community-dwelling women in Japan: the Hizen-Oshima Study, cross-sectional study. Rheumatol Int 2012;32:2245-9. Crossref

6. Hirase T, Inokuchi S, Matsusaka N, Okita M. Effectiveness of a balance-training program provided by qualified care workers for community-based older adults: a preliminary study. Geriatr Nurs 2015;36:219-23. Crossref

7. de Labra C, Guimaraes-Pinheiro C, Maseda A, Lorenzo T, MillánCalenti JC. Effects of physical exercise interventions in frail older adults: a systematic review of randomized controlled trials. BMC Geriatr 2015;15:154. Crossref

8. Fried LP, Tangen CM, Walston J, et al. Frailty in older adults: evidence for a phenotype. J Gerontol A Bio Sci Med Sci 2001;56:M146-56. Crossref

9. Faber MJ, Bosscher RJ, Chin A Paw MJ, van Wieringen PC. Effects of exercise programs on falls and mobility in frail and pre-frail older adults: a multicenter randomized controlled trial. Arch Phys Med Rehabil 2006;87:885-96. Crossref

10. Yamada M, Arai H, Sonoda T, Aoyama T. Community-based exercise program is cost-effective by preventing care and disability in Japanese frail older adults. J Am Med Dir Assoc 2012;13:507-11. Crossref

11. Arai $\mathrm{T}$, Obuchi $\mathrm{S}$, Sato $\mathrm{M}$, Noro $\mathrm{M}$. The relationships between the basic checklist score, physical function, and improvement in physical function [in Japanese]. Nihon Ronen Igakkai Zasshi 2010;47:585-91. Crossref

12. Mickle KJ, Munro BJ, Lord SR, Menz HB, Steele JR. ISB Clinical Biomechanics Award 2009: toe weakness and deformity increase the risk of falls in older people. Clin Biomech (Bristol, Avon) 2009;24:787-91. Crossref

13. Fong DT, Mao DW, Li JX, Hong Y. Greater toe grip and gentler heel strike are the strategies to adapt to slippery surface. J Biomech 2008;41:838-44. Crossref

14. Menz HB, Morris ME, Lord SR. Foot and ankle characteristics associated with impaired balance and functional ability in older people. J Gerontol A Biol Sci Med Sci 2005;60:1546-52. Crossref

15. Perry SD, Mcllroy WE, Maki BE. The role of plantar cutaneous mechanoreceptors in the control of compensatory stepping reactions evoked by unpredictable, multi-directional perturbation. Brain Res 2000;877:401-6. Crossref

16. Pavailler S, Hintzy F, Horvais N, Forestier N. Cutaneous stimulation at the ankle: a differential effect on proprioceptive postural control according to the participants' preferred sensory strategy. J Foot Ankle Res 2016;9:9. Crossref

17. Inglis JT, Kennedy PM, Wells C, Chua R. The role of cutaneous receptors in the foot. Adv Exp Med Biol 2002;508:111-7. Crossref

18. Takatori K, Matsumoto D. Relationships between simple toe elevation angle in the standing position and dynamic balance and fall risk among community-dwelling older adults. PM R 2015;7:1059-63. Crossref

19. Lelard T, Ahmaidi S. Effects of physical training on age-related balance and postural control. Neurophysiol Clin 2015;45:35769. Crossref

20. Tinetti ME, Speechley M, Ginter SF. Risk factors for falls among elderly persons living in the community. $\mathrm{N}$ Engl J Med 1988;319:1701-7. Crossref

21. Hasegawa M, Yamazaki S, Kimura M, Nakano K, Yasumura S. Community-based exercise program reduces chronic knee pain in elderly Japanese women at high risk of requiring long-term care: a non-randomized controlled trial. Geriatr Gerontol Int 2013;13:167-74. Crossref

22. Uritani D, Fukumoto T, Matsumoto D, Shima M. Associations between toe grip strength and hallux valgus, toe curl ability, and foot arch height in Japanese adults aged 20 to 79 years: a crosssectional study. J Foot Ankle Res 2015;8:18. Crossref

23. Spink MJ, Menz HB, Lord SR. Efficacy of a multifaceted podiatry intervention to improve balance and prevent falls in older people: study protocol for a randomised trial. BMC Geriatr 2008;8:30. Crossref

24. Misu S, Doi T, Asai T, et al. Association between toe flexor strength and spatiotemporal gait parameters in communitydwelling older people. J Neuroeng Rehabil 2014;11:143. Crossref

25. Uritani D, Fukumoto T, Matsumoto D, Shima M. Reference values for toe grip strength among Japanese adults aged 20 to 79 years: a cross-sectional study. J Foot Ankle Res 2014;7:28. Crossref

26. Vivanti AP, McDonald CK, Palmer MA, Sinnott M. Malnutrition associated with increased risk of frail mechanical falls among older people presenting to an emergency department. Emerg Med Australas 2009;21:386-94. Crossref

27. Legrand D, Adriaensen W, Vaes B, Matheï C, Wallemacq P, Degryse J. The relationship between grip strength and muscle mass $(\mathrm{MM})$, inflammatory biomarkers and physical performance in community-dwelling very old persons. Arch Gerontol Geriatr 2013;57:345-51. Crossref

28. Menz HB, Morris ME, Lord SR. Foot and ankle risk factors for falls in older people: a prospective study. J Gerontol A Biol Sci Med Sci 2006;61:866-70. Crossref

29. Cattagni T, Scaglioni G, Laroche D, Gremeaux V, Martin A. The involvement of ankle muscles in maintaining balance in the upright posture is higher in elderly fallers. Exp Gerontol 2016;77:38-45. Crossref

30. Nomura T, Nagano K, Takato J, Ueki S, MatsuzakiY, Yasumura S. The development of a Tai Chi exercise regimen for the prevention of conditions requiring long-term care in Japan. Arch Gerontol Geriatr 2011;52:e198-203. Crossref 